\title{
Antibiotic Resistance and Detection of the Most Common Mechanism of Resistance (MLSB) of Opportunistic Corynebacterium
}

\author{
Alina Olender \\ Department of Medical Microbiology, Medical University of Lublin, Lublin, Poland
}

\section{Key Words}

Antibiotic resistance Colonization - Corynebacterium . erm X $\cdot$ Infections $\cdot$ Multidrug resistance $\cdot$ MLSB detection . Nose colonization

\begin{abstract}
Background: Determination of antibiotic resistance of opportunistic Corynebacterium colonizing the nose that cause infections and evaluation of the applicability of a simple method for detecting the most common constitutive-type resistance to macrolides, lincosamides and streptogramin B (MLSB). Methods: 70 isolates colonizing the nose and 70 clinical isolates of various infection sites were used and identified using APICoryne and 16S rRNA. Minimal inhibitory concentrations (MICs) were determined (Etest) for 12 antibiotics. MLSB was defined based on MIC, a simple method using two disks (erythromycin/clindamycin) and detection of the gene erm X (PCR). Results: There was a high percentage - in both groups at the same level - of strains with MLSB $(88.5 \%$ colonizing the nose and $87.1 \%$ causing infections). Detection with the phenotypic method MLSB was confirmed genetically (erm X) in all cases. In both groups, a high percentage of resistance was found to trimethoprim/sulfamethoxazole (in both groups $71.4 \%$ ), chloramphenicol (nose $44.2 \% /$ infec-
\end{abstract}

tions $37.1 \%)$, tetracycline ( 28 and $45.7 \%$ ) and $\beta$-lactam antibiotics (18.5 and up to $32.8 \%$ ). Conclusion: Differences in antibiotic resistance were found between strains colonizing the respiratory tract and various infections. Isolates from infections more frequently exhibited multidrug resistance. The possibility of using a simple method was confirmed for MLSB detection, which can be applied to determine drug resistance in routine microbiological diagnostics of infections caused by opportunistic Corynebacterium.

(c) 2014 S. Karger AG, Basel

\section{Introduction}

The Corynebacterium genus includes a very large group of species with different phenotypic traits and pathogenic effects. More than 90 species belonging to the genus Corynebacterium have been described, and this number is increasing every year by newly identified or reclassified strains. Besides the most important species in terms of pathogenic activity, toxigenic C. diphtheriae, there are species in the physiological flora of the upper respiratory tract and skin, which, as opportunistic organisms in favorable circumstances, can also cause infection in humans. Due to their pathogenic significance, the most

\section{KARGER}

E-Mail karger@karger.com www.karger.com/che (c) 2014 S. Karger AG, Basel

0009-3157/14/0594-0294\$39.50/0
Alina Olender

Department of Medical Microbiology

Medical University of Lublin

W. Chodzki 1, PL-20093 Lublin (Poland)

E-Mail a.olender@umlub.pl 
important may be considered: C. jeikeium [1,2], C. urealyticum [3], C. amycolatum [4], C. striatum [5-7], C. pseudodiphtheriticum $[8,9]$ and C. macginleyi [10]. Infections caused by the opportunistic species of the genus Corynebacterium include bacteremia, sepsis, endocarditis, valvular damage, meningitis and infections of the urinary tract, the respiratory tract, wounds, skin and eye. The potential for infections of endogenous nature points to the Corynebacterium spp. strains included in the physiologi$\mathrm{cal}$ flora and their resistance to antibiotics. The extent to which they correlate with the strains isolated from infections is very important. One of the most serious problems related to treatment of infections caused by Corynebacterium spp. is the isolation of multidrug-resistant species from clinical material and the selection of the appropriate antibiotic therapy for a given type of infection. The information about high levels of antibiotic resistance (high values of minimal inhibitory concentration, MIC) are primarily based on the results of previous phenotypic studies on different species of Corynebacterium spp. [6, 11-13]. There are different mechanisms of resistance, which result from the expression of the responsible genes, e.g. resistance to tetracycline (the tet $\mathrm{A}$, tet $\mathrm{B}$ and tet $\mathrm{M}$ genes) $[14,15]$ or fluoroquinolones (single or multiple mutations within gyrase subunit A) $[16,17]$, and resistance to macrolides, lincosamides and streptogramin B (MLSB) frequently occurs in opportunistic Corynebacterium spp. $[18,19]$.

The aim of this study was to analyze differences in antibiotic resistance between Corynebacterium strains from the upper respiratory tract (the nose), as a component of the physiological flora, and strains responsible for various opportunistic infections. The analysis paid special attention to the most common mechanism of resistance that occurs in both groups of strains examined. Another aim was to evaluate the application of simple phenotypic methods in the detection of the most common mechanism of resistance, which may be applicable in the routine microbiological diagnostics of infections caused by opportunistic Corynebacterium (coryneform).

\section{Materials and Methods}

\section{Cultures and Identification}

The two groups of strains used in this study (140 isolates of Gram-positive bacteria of the genus Corynebacterium in total) were obtained in 2008-2011. The first group of 70 strains was derived from cultures of nasal swabs from subjects in whom diagnostic microbiological testing was performed due to infection of the upper respiratory tract. The strains isolated were grown in mono- culture and showed abundant growth on the substrate. The other group examined consisted of 70 strains of Corynebacterium spp. isolated from clinical material from routine microbiological diagnostics of various infections. The clinical material came from a diverse group of patients, both inpatients and outpatients. The strains were isolated from wounds $(n=25)$, blood $(n=14)$, eye $(n=7)$, ear $(n=5)$, sputum $(n=4)$, pleural fluid $(n=3)$, urine $(\mathrm{n}=3)$, vagina $(\mathrm{n}=3)$, tracheostomy tube $(\mathrm{n}=2)$, catheter insertion site $(\mathrm{n}=1)$, dialysis fluid $(\mathrm{n}=1)$, peritoneal fluid (1) and bronchial aspirate $(\mathrm{n}=1)$.

Cultures were performed on Columbia agar base with $5 \%$ sheep blood (bioMérieux, Marcy l'Etoile, France). Incubation was carried out in aerobic conditions at $37^{\circ} \mathrm{C}$ for $24-48 \mathrm{~h}$. After isolation, the strains were stored in cryovials (Microbank; PRO-LAB Diagnostics, Richmond Hill, Ont., Canada) at -20 and $-70^{\circ} \mathrm{C}$ for further tests.

All strains were identified based on the phenotypic traits. Identification was carried out based on the morphological traits of colonies and microscopic features using the Gram stain method and sets of biochemical tests to identify species of the genus Corynebacterium (APICoryne combined with APIZYM and APINE; bioMérieux). The results were read using apiweb ${ }^{\circledR}$ (bioMérieux). The strains were subjected to genetic identification consisting of an analysis of the sequence of the encoding gene fragment 16S rRNA [20-22] (Laboratory of Sequences, DNA IBB PAN, oligo.pl) to validate the correctness of the identified species that caused problems in the phenotypic identification. Analysis of the results was performed based on the GenBank database using the BLAST program.

\section{Determination of MICs}

Determination of MIC ( $\mathrm{mg} / \mathrm{l})$ values was performed using the Etest (bioMérieux) on Mueller-Hinton agar base with 5\% sheep blood (bioMérieux) using an inoculum at a density of 1.0 on the McFarland scale. Incubation was carried out at $35^{\circ} \mathrm{C}$ in oxygen atmosphere or in $5 \% \mathrm{CO}_{2}$ - if it was necessary for a better growth of the test strain (not in the case of erythromycin and clindamycin, as suggested by the manufacturer) for $24-48 \mathrm{~h}$. The interpretation of MIC values for benzylpenicillin, ceftriaxone, cefotaxime, clindamycin, erythromycin, imipenem, ciprofloxacin, vancomycin, tetracycline and trimethoprim/sulfamethoxazole was carried out in accordance with the recommendations for Corynebacterium spp. $[23,24]$. Due to the lack of established criteria for the interpretation of teicoplanin and chloramphenicol, the recommendations of the Clinical and Laboratory Standards Institute for Staphylococcus aureus were used [25].

\section{Resistance Mechanism to Macrolides, Lincosamides and} Streptogramin B (MLSB) - The Double-Disk Method

The study was performed on Mueller-Hinton agar base with $5 \%$ sheep blood (bioMérieux) using an inoculum at a density of 1.0 on the McFarland scale. Disks with erythromycin $(15 \mu \mathrm{g})$ and clindamycin $(2 \mu \mathrm{g})$ (Becton Dickinson, Sparks, Md., USA) were placed at a distance of $26 \mathrm{~mm}$. Incubation was carried out at $35^{\circ} \mathrm{C}$ in oxygen atmosphere. The interpretation of the zones of growth inhibition, read in millimeters, was performed for erythromycin and clindamycin in the same way as for staphylococci and streptococci $[19,25,26]$. S. aureus ATCC 29213 was used as the control strain.

On the basis of the results, presence of the phenotypic crossresistance mechanism MLSB was determined for macrolides, lin- 
Table 1. Strains of the genus Corynebacterium spp. isolated from the nasal mucous membranes $(\mathrm{n}=70)$

\begin{tabular}{llrc}
\hline \multirow{2}{*}{ Species } & \multicolumn{2}{c}{ Isolated strains } \\
\cline { 3 - 4 } & $\mathrm{n}$ & $\%$ \\
\hline 1 & C. pseudodiphtheriticum & 28 & 40.0 \\
2 & C. accolens & 11 & 15.7 \\
3 & C. propinquum & 8 & 11.4 \\
4 & C. amycolatum & 7 & 10.0 \\
5 & C. striatum & 7 & 10.0 \\
6 & C. tuberculostearicum & 5 & 7.2 \\
7 & C. macginleyi & 2 & 2.9 \\
8 & C. group F1 & 1 & 1.4 \\
9 & C. pseudogenitalium & 1 & 1.4 \\
\hline
\end{tabular}

cosamides and streptogramin B in all test strains. Lack of growth inhibition around the disk of erythromycin and clindamycin in both test distances was considered a positive result for the presence of the constitutive-type resistance MLSB.

Study of the Presence of the Gene erm X Using PCR in Strains with the Phenotypically Identified Resistance Mechanism $M L S B$

Bacterial DNA was obtained by heating a suspension of 2-3 colonies in $0.5 \mathrm{ml}$ of sterile deionized water at $90^{\circ} \mathrm{C}$ for $10 \mathrm{~min}$ followed by centrifugation at $15,000 \mathrm{~g}$ for $2 \mathrm{~min}$. The resulting supernatant containing DNA was frozen at $-20^{\circ} \mathrm{C}$ and stored until analyzed. The negative control was sterile deionized water. PCR was performed using the following primers [19]: Crm1: GACACGGCCGTCACGAGCAT, Crm2: GGCGGCGAGCGACTTCC (Laboratory of Sequence, DNA IBB PAN, oligo.pl). The PCR amplification cycle included: $95^{\circ} \mathrm{C}$ for $5 \mathrm{~min}$, followed by 35 cycles at $95^{\circ} \mathrm{C}$ for $1 \mathrm{~min}, 65^{\circ} \mathrm{C}$ for $1 \mathrm{~min}, 72^{\circ} \mathrm{C}$ for $2 \mathrm{~min}$ and $72^{\circ} \mathrm{C}$ for $5 \mathrm{~min}$. PCR products were electrophoretically separated in $1.5 \%$ agarose gel (Sigma, St. Louis, Mo., USA) in Tris-phosphate-EDTA buffer 1:10 (Sigma) containing $1 \mu \mathrm{g} / \mu \mathrm{l}$ ethidium bromide. The following markers were used for the sizes of PCR products: 250, 500, 750, 1,000 and 10,000 bp (GeneRuler Fermentas). The result was considered positive (erm X gene present) if a PCR product of $390 \mathrm{bp}$ was obtained. The results of the gel image were archived using Kodak EDAS 290

\section{Results}

C. pseudodiphtheriticum (28/40\%), C. accolens (11/ $15.7 \%)$ and C. propinquum (8/11.4\%) were the most common isolates in the group of strains derived from the mucous membranes of the nose (table 1). It is worth noting that as many as 5 strains of $C$. tuberculostearicum were isolated from samples of infections; C. pseudogenitalium, which may be part of the physiological flora of urogenital organs, was also isolated from the nose.
Table 2. Isolated strains of Corynebacterium spp. $(n=70)$ from various infection sites

\begin{tabular}{|c|c|c|}
\hline Source & Species isolated & $\mathrm{n}$ \\
\hline $\begin{array}{l}\text { Wound swab } \\
(\mathrm{n}=25)\end{array}$ & $\begin{array}{l}\text { C. amycolatum } \\
\text { C. striatum } \\
\text { C. jeikeium } \\
\text { C. group G } \\
\text { C. group F1 } \\
\text { C. urealyticum }\end{array}$ & $\begin{array}{l}7 \\
6 \\
4 \\
4 \\
2 \\
2\end{array}$ \\
\hline $\begin{array}{l}\text { Blood } \\
(\mathrm{n}=14)\end{array}$ & $\begin{array}{l}\text { C. amycolatum } \\
\text { C. jeikeium } \\
\text { C. striatum } \\
\text { C. glucuronolyticum }\end{array}$ & $\begin{array}{l}9 \\
2 \\
2 \\
1\end{array}$ \\
\hline $\begin{array}{l}\text { Eye conjunctival swab } \\
(\mathrm{n}=7)\end{array}$ & $\begin{array}{l}\text { C. amycolatum } \\
\text { C. striatum } \\
\text { C. aurimucosum } \\
\text { C. macginleyi } \\
\text { C. propinquum }\end{array}$ & $\begin{array}{l}2 \\
2 \\
1 \\
1 \\
1\end{array}$ \\
\hline $\begin{array}{l}\text { Ear swab } \\
(\mathrm{n}=5)\end{array}$ & $\begin{array}{l}\text { C. accolens } \\
\text { C. afermentans } \\
\text { C. amycolatum } \\
\text { C. propinquum } \\
\text { C. striatum }\end{array}$ & $\begin{array}{l}1 \\
1 \\
1 \\
1 \\
1\end{array}$ \\
\hline $\begin{array}{l}\text { Sputum } \\
(\mathrm{n}=4)\end{array}$ & $\begin{array}{l}\text { C. pseudodiphtheriticum } \\
\text { C. propinquum }\end{array}$ & $\begin{array}{l}3 \\
1\end{array}$ \\
\hline $\begin{array}{l}\text { Pleural fluid } \\
(\mathrm{n}=3)\end{array}$ & $\begin{array}{l}\text { C. amycolatum } \\
\text { C. macginleyi } \\
\text { C. propinquum }\end{array}$ & $\begin{array}{l}1 \\
1 \\
1\end{array}$ \\
\hline $\begin{array}{l}\text { Urine } \\
(\mathrm{n}=3)\end{array}$ & $\begin{array}{l}\text { C. striatum } \\
\text { C. pseudodiphtheriticum }\end{array}$ & $\begin{array}{l}2 \\
1\end{array}$ \\
\hline Vaginal swab $(\mathrm{n}=3)$ & C. striatum & 3 \\
\hline $\begin{array}{l}\text { Tracheostomy secretion } \\
(\mathrm{n}=2)\end{array}$ & $\begin{array}{l}\text { C. amycolatum } \\
\text { C. glucuronolyticum }\end{array}$ & $\begin{array}{l}1 \\
1\end{array}$ \\
\hline $\begin{array}{l}\text { Catheter injection site } \\
(\mathrm{n}=1)\end{array}$ & C. group G & 1 \\
\hline Dialysis fluid $(\mathrm{n}=1)$ & C. afermentans & 1 \\
\hline Peritoneal fluid $(\mathrm{n}=1)$ & C. urealyticum & 1 \\
\hline Bronchial aspirate $(\mathrm{n}=1)$ & C. pseudodiphtheriticum & 1 \\
\hline
\end{tabular}

In the second group of strains of Corynebacterium spp. (table 2) isolated from various human infections, the most common isolates in humans were C. amycolatum (21/30\%), C. striatum (16/22.8\%) and C. jeikeium (6/ $8.6 \%)$. Thirteen different species were isolated from the study material.

Ranges of MIC and $\mathrm{MIC}_{50}$ and $\mathrm{MIC}_{90}$ values for the antibiotics determined for the study strains are presented 
Fig. 1. Comparison of antibiotic-resistant strains of Corynebacterium spp. isolated from the nasal mucous membranes and various infection sites (abbreviations are explained in table 4).

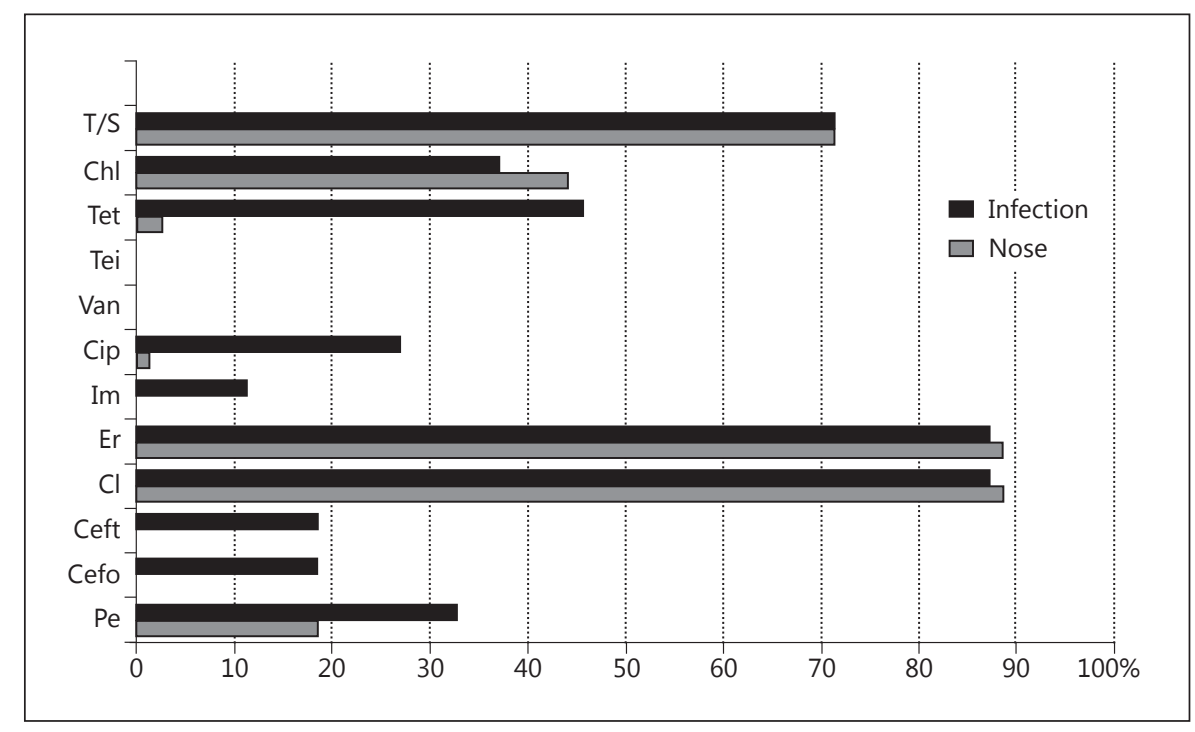

Table 3. Comparison of the MIC (mg/l) range, $\mathrm{MIC}_{50}$ and $\mathrm{MIC}_{90}$ of the antibiotics for strains of the genus Corynebacterium from the physiological flora of the nose and various infection sites

\begin{tabular}{|c|c|c|c|c|c|c|c|}
\hline & \multirow[t]{2}{*}{ Antibiotics } & \multicolumn{3}{|c|}{$\begin{array}{l}\text { Corynebacterium spp. from the nose } \\
(\mathrm{n}=70)\end{array}$} & \multicolumn{3}{|c|}{$\begin{array}{l}\text { Corynebacterium spp. from various infec- } \\
\text { tion sites }(\mathrm{n}=70)\end{array}$} \\
\hline & & MIC range & $\mathrm{MIC}_{50}$ & $\mathrm{MIC}_{90}$ & MIC range & $\mathrm{MIC}_{50}$ & $\mathrm{MIC}_{90}$ \\
\hline 1 & Benzylpenicillin & $\leq 0.016$ to $\geq 256$ & 0.032 & 12.0 & 0.023 to $\geq 256$ & 0.125 & 256 \\
\hline 2 & Cefotaxime & $\leq 0.016$ to 0.75 & 0.094 & 0.125 & 0.023 to $\geq 256$ & 0.125 & 24 \\
\hline 3 & Ceftriaxone & $\leq 0.016$ to 0.75 & 0.032 & 0.125 & 0.023 to $\geq 256$ & 0.125 & 24 \\
\hline 4 & Clindamycin & 0.064 to $\geq 256$ & 256 & 12.0 & 0.023 to $\geq 256$ & 256 & 256 \\
\hline 5 & Erythromycin & 0.064 to $\geq 256$ & 256 & 12.0 & 0.023 to $\geq 256$ & 256 & 256 \\
\hline 6 & Imipenem & $\leq 0.002$ to 1.5 & 0.006 & 0.032 & $\leq 0.002$ to 32 & 0.008 & 32 \\
\hline 7 & Ciprofloxacin & 0.012 to 32 & 0.125 & 0.75 & 0.012 to 32 & 0.25 & 32 \\
\hline 8 & Vancomycin & 0.032 to 1.0 & 0.25 & 1.0 & 0.032 to 1.5 & 0.25 & 1.0 \\
\hline 9 & Teicoplanin & 0.023 to 4.0 & 1.0 & 2.0 & 0.032 to 6.0 & 1.0 & 4.0 \\
\hline 10 & Tetracycline & 0.023 to $\geq 256$ & 0.5 & 2.0 & 0.032 to $\geq 256$ & 6.00 & 256 \\
\hline 11 & Chloramphenicol & 0.023 to $\geq 256$ & 256 & 256 & 0.032 to $\geq 256$ & 4.00 & 256 \\
\hline 12 & Trim./sulfameth. & 0.12 to $\geq 32$ & 32 & 32 & 0.38 to $\geq 32$ & 32 & 32 \\
\hline
\end{tabular}

in tables 3 and 4 . They are particularly high for macrolides and lincosamides $(256 \mathrm{mg} / \mathrm{l})$, and there are also highly susceptible isolates with MIC values of 0.064 and 0.125 $\mathrm{mg} / \mathrm{l}$. MIC values were particularly low in all strains for imipenem, which indicates a high efficiency of this antibiotic against Corynebacterium spp. Vancomycin and teicoplanin are the antibiotics to which all tested isolates were susceptible. $\mathrm{MIC}_{50}$ and $\mathrm{MIC}_{90}$ values were increased for almost all strains of Corynebacterium spp. for chloramphenicol (256 mg/l) and trimethoprim/sulfamethoxazole $(32 \mathrm{mg} / \mathrm{l})$. In case of strains isolated from infections, high resistance to tetracycline (45.7\%) and benzylpenicil- lin $(32.8 \%)$ was noted. Since certain strains (C. aurimucosum and C. accolens) were isolated from infections separately, the determined MIC values certainly do not characterize full resistance of these species to antibiotics (table 4). Special attention, due to their high resistance, should be paid to C. striatum and C. amycolatum, which are the most common isolates from infections, as well as strains of C. jeikeium and C. macgilneyi.

In both groups of strains isolated from the nose and infections, a high percentage of strains was also resistant to macrolides (erythromycin) and lincosamides (clindamycin), which indicates a frequent occurrence of cross- 


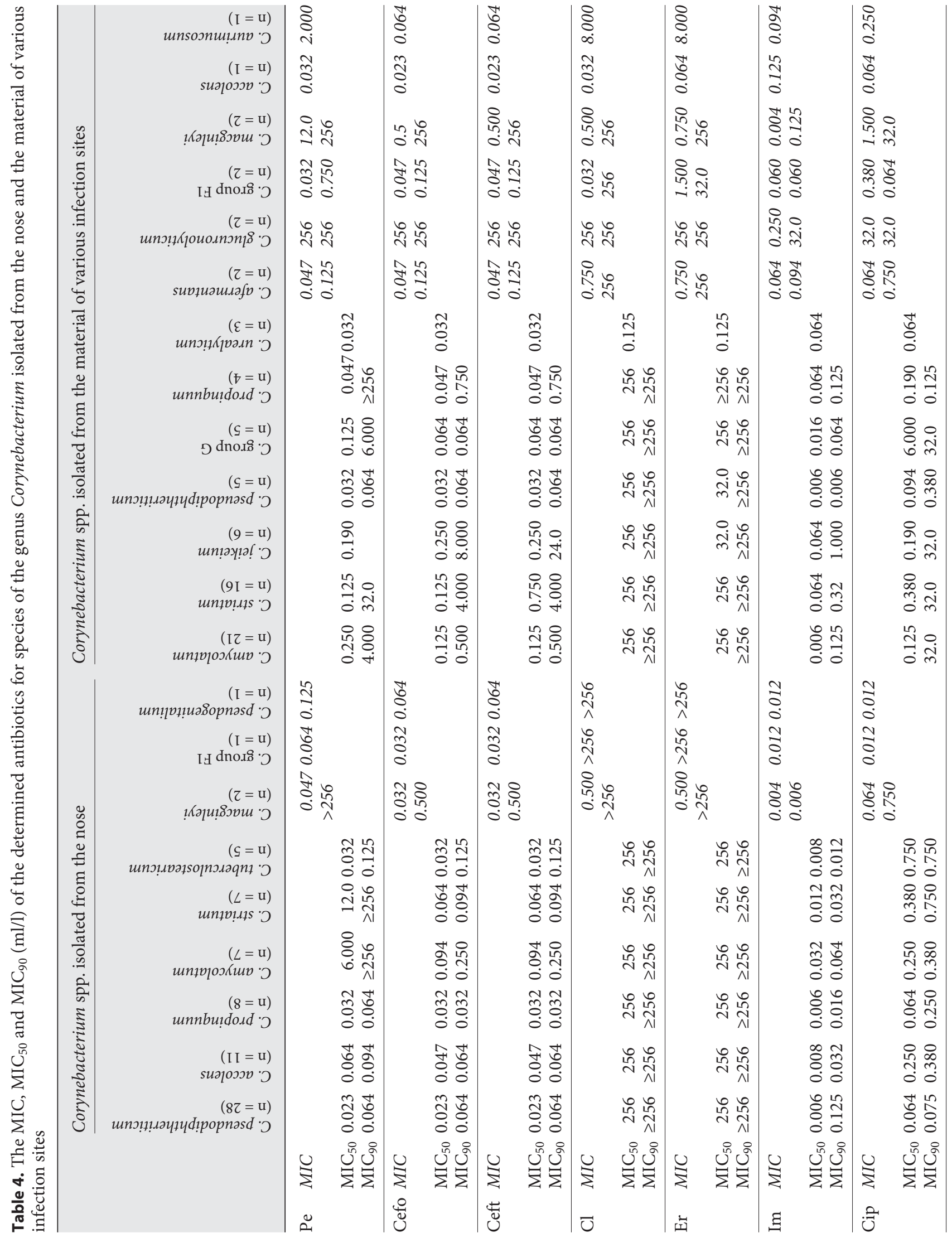




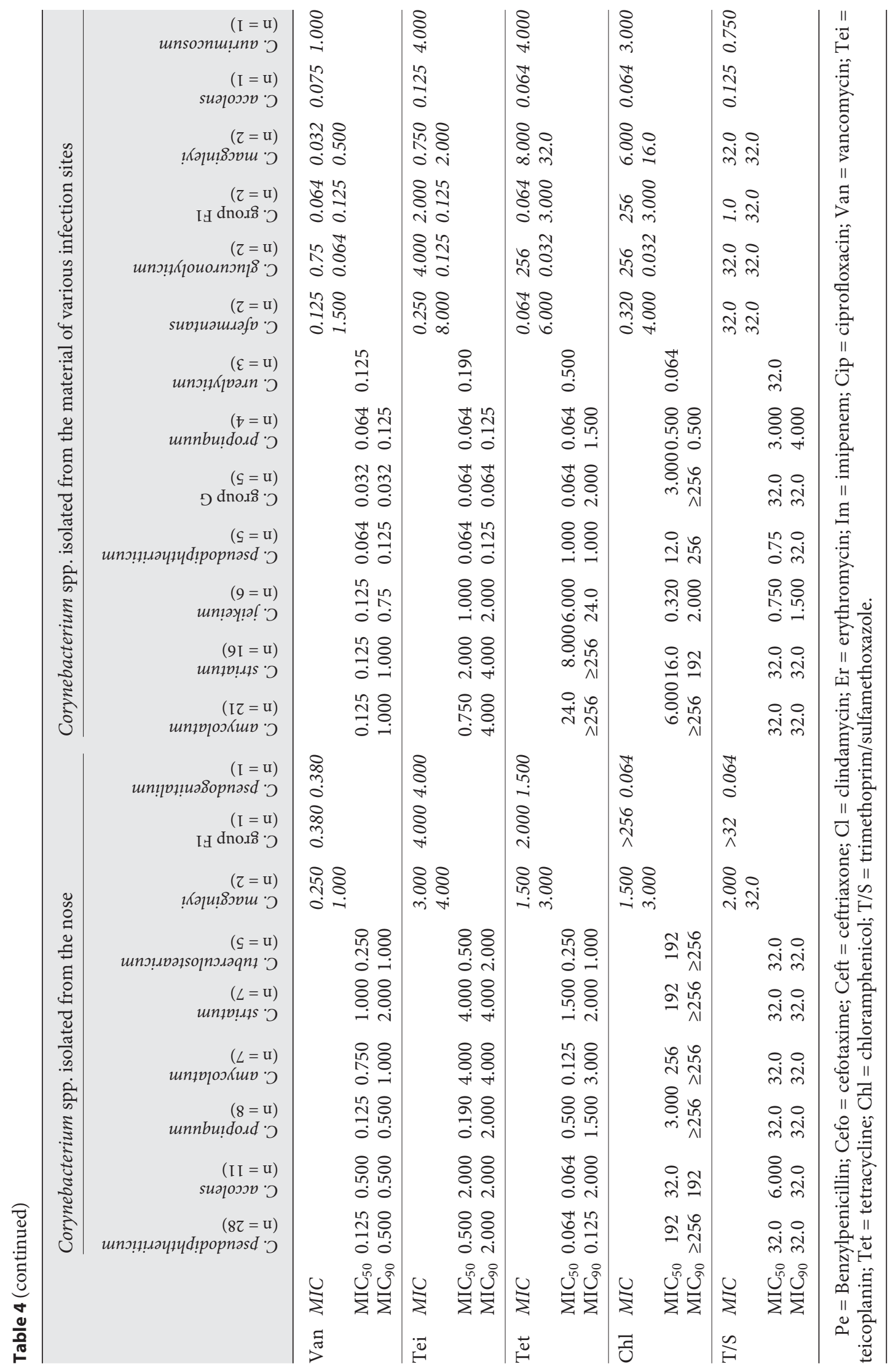




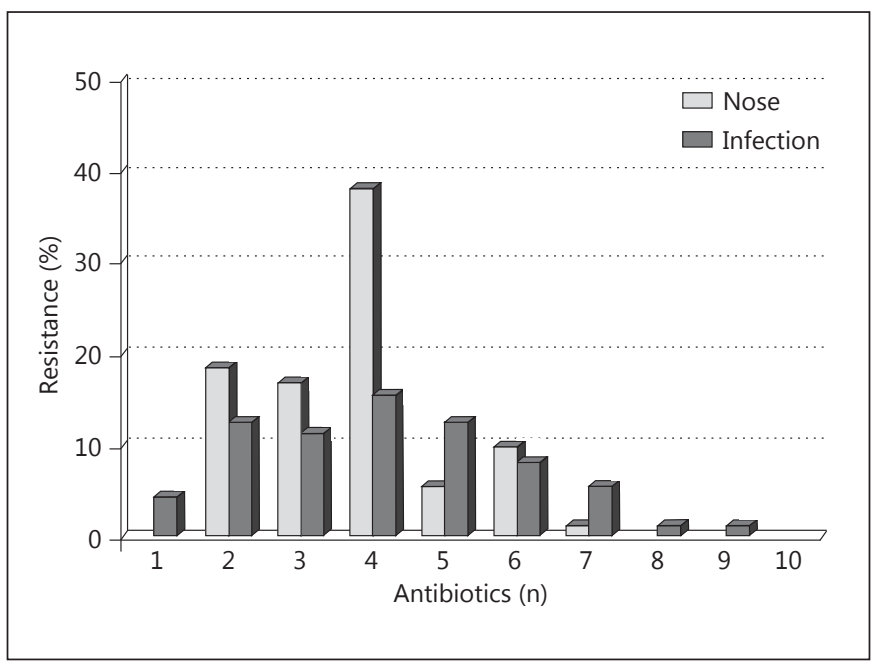

Fig. 2. Comparison of strains from the nose and various infection sites that were simultaneously resistant to one or more antibiotics.

resistant MLSB (tables 3, 4). It is noteworthy (fig. 1) that the percentage of the antibiotic-resistant strains is almost the same (difference: 1 isolate) for the isolates from the nasal mucous membranes $(88.5 \%)$ and the isolates from the various infections (87.1\%), and there is a high level of resistance in both study groups (71.4\%) to trimethoprim/ sulfamethoxazole. Chloramphenicol was another antibiotic to which the isolates showed increased resistance. The resistance of strains derived from the nasal mucous membranes was $44.2 \%$, while it was $37.1 \%$ in those isolated from infections. With respect to the other antibiotic groups, resistance turned out to be much higher for the isolates derived from infections. One example is tetracycline, to which resistance of the strains isolated from infections amounted to $45.7 \%$, while resistance was only $2.8 \%$ in those from the nose. This is confirmed by MIC values (table 4). Corynebacterium spp. isolated from the nose was resistant to $\beta$-lactam antibiotics (18.5\%), while $\beta$-lactam resistance of those from infections ranged between 18.5 and $32.8 \%$.

In Corynebacterium spp. isolated from the nose, the highest multiresistance was usually reported for four antibiotics (38.5\%) simultaneously in one isolate (fig. 2). These are mainly clindamycin, erythromycin, chloramphenicol and trimethoprim/sulfamethoxazole, and the highest resistance was to six antibiotics (penicillin, clindamycin, erythromycin, tetracycline, chloramphenicol and trimethoprim/sulfamethoxazole).

Detection of cross-resistance to macrolides, lincosamides and streptogramin B (MLSB) using the double-

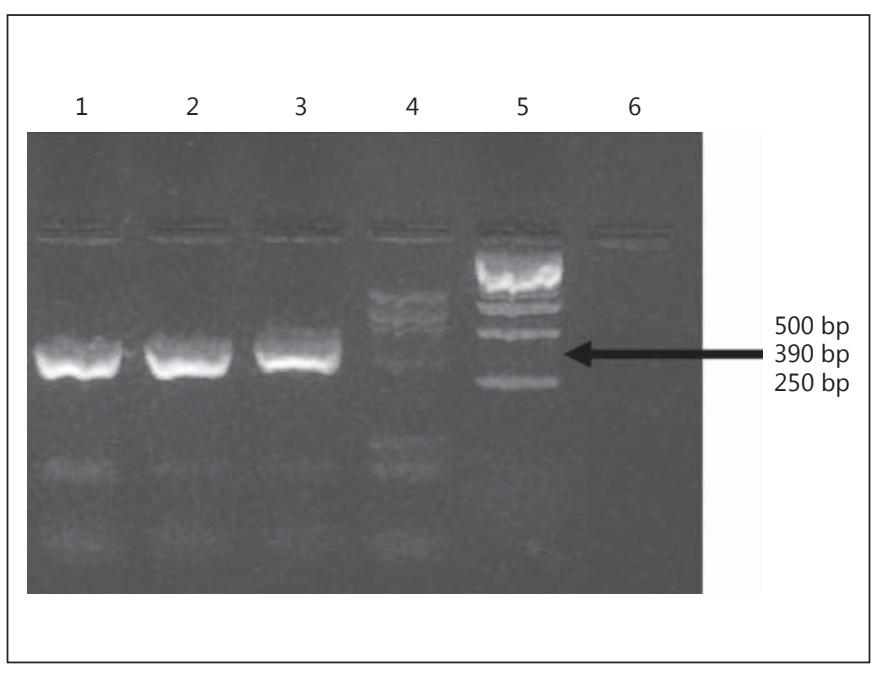

Fig. 3. Sample results of the determination of PCR: identification of gene erm $(\mathrm{X})$ resistance among the Corynebacterium strains. $1=$ C. propinquum; $2=$ C. amycolatum $3=$ C. accolens $; 4=C$. striatum $=$ negative; $5=$ standard size containing a fragment of 390 bp corresponding to the location of the band of the detected gene erm $\mathrm{X} ; 6$ = control $-\mathrm{H}_{2} \mathrm{O}$.

disk method, which is applied for staphylococci and streptococci, was confirmed in all strains, in which the determined MIC values showed resistance to clindamycin and erythromycin. In Corynebacterium spp. from the nose, the MLSB mechanism occurred in 62 strains (88.5\%) versus 61 strains $(87.1 \%)$ in isolates from infections. In all cases, the constitutive-type resistance mechanism was found.

The strains of Corynebacterium spp. from both groups for which the MIC values for clindamycin and erythromycin showed simultaneous resistance to these two antibiotics were used to detect the presence of gene erm X by PCR. Finally, MLSB resistance (lack of the gene erm X) was not found in strains with MIC values similar to moderately susceptible. The gene erm X was detected in all strains with the constitutive-type mechanism MLSB by the double-disk method with clindamycin and erythromycin (fig. 3). A summary of the results of the three methods of MLSB mechanism detection is presented in table 5 .

In the opportunistic infections analyzed, more and more attention is attracted by bacteria of the genus Corynebacterium, which were previously known as diphtheroids but are presently referred to as coryneform strains. These club-like Gram-positive bacteria are commonly found on mucous membranes and the skin, and can cause serious life-threatening infections, even leading to death 
Table 5. Summary results of the determination of MLSB resistance using the phenotypic method (the double-disk test with $15 \mu \mathrm{g}$ erythromycin and $2 \mu \mathrm{g}$ clindamycin), MIC (Etest) and gene erm X detection by the PCR method based on 80 strains of Corynebacterium from the nose and various other infection sites

\begin{tabular}{|c|c|c|c|c|c|c|}
\hline \multirow[t]{2}{*}{ Species (strain numbers and their origin) } & \multicolumn{2}{|c|}{$\begin{array}{l}\text { MLSB - } \\
\text { double-disk test }\end{array}$} & \multicolumn{2}{|c|}{$\begin{array}{l}\text { MIC } \\
\text { (Etest) }\end{array}$} & \multicolumn{2}{|c|}{$\begin{array}{l}\text { Presence of gene } \\
\text { erm X by PCR }\end{array}$} \\
\hline & pos. & neg. & pos. & neg. & pos. & neg. \\
\hline C. pseudodiphtheriticum (29: nose, 25; urine, 1; sputum, 2; BA, 1) & 27 & 2 & 27 & 2 & 27 & 2 \\
\hline C. accolens (11: nose, 10 ; ear, 1$)$ & 9 & 2 & 9 & 2 & 9 & 2 \\
\hline C. amycolatum (10: nose, 5; blood, 3; wound, 2) & 9 & 1 & 9 & 1 & 9 & 1 \\
\hline C. striatum (10: nose, 6 ; wound, 3 ; blood, 1 ) & 8 & 2 & 8 & 2 & 8 & 2 \\
\hline C. propinquum (6: nose, 5 ; sputum, 1 ) & 5 & 1 & 5 & 1 & 5 & 1 \\
\hline C. tuberculostearicum (5: nose) & 5 & 0 & 5 & 0 & 5 & 0 \\
\hline C. jeikeium (3: blood, 2; wound, 1) & 2 & 1 & 2 & 1 & 2 & 1 \\
\hline C. afermentans (2: ear, 1 ; dialysis fluid, 1 ) & 2 & 0 & 2 & 0 & 2 & 0 \\
\hline C. aurimucosum (1: eye conjunctiva) & 1 & 0 & 1 & 0 & 1 & 0 \\
\hline C. macginleyi (1: nose) & 0 & 1 & 0 & 1 & 0 & 1 \\
\hline C. pseudogenitalium (1: nose) & 1 & 0 & 1 & 0 & 1 & 0 \\
\hline C. urealyticum (1: peritoneal fluid) & 1 & 0 & 1 & 0 & 1 & 0 \\
\hline
\end{tabular}

pos. = Positive MLSB; neg. = negative MLSB; BA = bronchial aspirate

of the patient. Undoubtedly, a very important additional problem associated with the occurrence of infections caused by this group of microorganisms is the emergence of coryneform strains in recent years which are simultaneously resistant to several classes of antibiotics as well as the emergence of new multiresistant species such as $C$. resistens [27].

In this study, including 140 strains of Corynebacterium spp. derived from the physiological flora of the nose and a variety of infections in humans, thanks to the use of both methods of identification, phenotypic and genotypic identification, it was possible to finally determine the species to which the isolates belonged. Thus, based on the morphological and biochemical traits, identification of as many as 30 strains proved to be insufficient, and only the application of the genetic method allowed the correct identification of the strains.

The strains of Corynebacterium that cause infections may come from the patient's environment or his physiological flora. The mucous membranes of the nose are a significant, potential source of endogenous infections.

In Corynebacterium spp. derived from the nose of our outpatients, the highest percentage of strains found was C. pseudodiphtheriticum, whereas in the group of isolates obtained from infections, the most frequent strains were C. striatum and C. amycolatum.
The presence of such a large number of C. pseudodiphtheriticum is undoubtedly connected with the involvement of these species in respiratory tract infections. They can cause pneumonia [28], bronchitis [29], especially in immunodeficient patients, and respiratory tract infections in children with cystic fibrosis of the pancreas [30]. In hospitalized patients, they are sometimes the cause of complications of endotracheal intubation leading to lower respiratory tract infections.

The results of this study on strains of Corynebacterium derived from a variety of infections confirmed previous reports in the literature on relationships between C. pseudodiphtheriticum and respiratory tract infections. In the group studied, C. pseudodiphtheriticum was isolated from the sputum of patients with pneumonia, bronchial aspirates and urine, which also indicates the possibility of urinary tract infections, as reported by other authors.

The second most common species isolated from the nose was C. accolens, some strains of which required genotypic identification in this study due to the difficulty in identifying the phenotype. Although C. accolens is a component of the physiological flora of the nose, it was described as a cause of breast abscess [31], endocarditis, cardiovalvulitis [32] and osteomyelitis [33]. A small proportion of these species in infections is confirmed by own studies. They were isolated only once, from the otitis media, and the location of the infection may result 
from their common occurrence on nasal mucous membranes.

C. propinquum is the next species in terms of the frequency of occurrence in the group tested. It is a common commensal of the nasopharynx and may cause infections of the respiratory tract, mostly in hospitalized patients [34]. The association of the colonization site with the location of the infection is also confirmed in this study. $C$. propinquum was a cause of pneumonia, otitis media, pleurisy and also caused conjunctivitis in the group of infections analyzed. Of note, among the strains isolated from the nose, C. tuberculostearicum and C. pseudogenitalium are rare. The presence of both species was confirmed genetically.

Other species such as C. amycolatum and C. striatum, which were isolated from the nose, belong to opportunistic Corynebacterium, which frequently cause infections in humans. Their presence indicates a possible source of infection derived from their colonization site, but the large number of cases of infections caused by C. amycolatum and $C$. striatum suggests that the nasal mucous membranes are not the most important source of their origin predisposing to infections. These strains can also come from the physiological flora of the skin or from the environment of the patient, and the nature of the infection may be exogenous.

In the present work, the second group under study included strains of Corynebacterium spp. isolated from clinical material, which came from infections of different locations in patients. This variety of infection sites from which the opportunistic Corynebacterium spp. were obtained confirms the high adaptability of these little virulent bacteria to different environments in the human body. It also indicates the possibility of more frequent and more diverse infections caused by microorganisms derived from the natural physiological flora of humans.

In the group of strains isolated from infections, C. striatum and C. amycolatum as well as $C$. jeikeium were the most frequent. In general, in this study group, a great diversity of species was found. Some of them were the cause of infections localized in different sites, such as C. striatum and C. amycolaum, whereas others occurred individually, e.g. C. accolens or C. aurimucosum, which may indicate their occasional contribution to opportunistic infections, although C. accolens, for example, was isolated in large quantities from nasal mucous membranes.

The most common strain, C. striatum, is an important opportunistic pathogen that may show multiresistance [35]. This observation is confirmed by the disturbing news about the discovery of a multidrug-resistant clone of C. striatum in Italy, which was isolated from infections in long-term inpatients [5]. In agreement with this study, its contribution to infections of the blood [36], wounds $[35,37]$ and the respiratory tract $[38]$ was confirmed. The case reports indicate the special incidence of this type of infection in long-term hospitalized patients.

In this study, this relationship was not observed. The material from which C. striatum was isolated had been selected at random and came from a diverse group of patients who were not hospitalized for a long period. These infection-causing species should not only be associated with patients hospitalized for a long time. However, the occurrence of antibiotic-resistant C. striatum in the hospital environment has been confirmed by studies of Campanile et al. [5].

In the present study, in order to be able to characterize and compare the antibiotic susceptibility of species of different origin (from the nose and from clinically confirmed infections), MIC values were determined for 12 antibiotics and chemotherapeutics by the method recommended for this group of microorganisms (Etest) [24,25]. Application of the testing method using Etests for the determination of antibiotic susceptibility of Corynebacterium spp. was indicated in works of many authors $[16,17$, 39]. It is particularly useful and reliable for bacteria of Corynebacterium spp., which also include strains with lipophilic properties and those requiring substances that enrich the medium, such as Tween 80 . On the other hand, using the Etest enables extension of the time of incubation in such cases, resulting in good comparability and reliability of the results for all Corynebacterium spp. regardless of their lipophilic properties.

In this study, the main difference between the groups of Corynebacterium analyzed was the higher susceptibility to antibiotics of strains colonizing the nasal mucous membranes, particularly with respect to $\beta$-lactam antibiotics.

These observations were confirmed by the analysis of drug resistance, e.g. strains of C. macginleyi, which were isolated in both study groups. A significantly higher resistance was shown by the strains isolated from infections, whereas other authors stress their general susceptibility to antibiotics. For example, Espínola et al. [40] studied C. macginleyi isolated from the skin, which caused conjunctivitis, and found that among 33 strains, resistance occurred only in 1 isolate to ciprofloxacin and in 2 to tetracyclines. All strains were susceptible to the other antibiotics. Unfortunately, resistance to macrolides and lincosamides was not determined, i.e. antibiotics to which a very high resistance was found in this study. 
Examination of Corynebacterium spp. derived from the nasal mucous membranes revealed very important information: the general susceptibility to vancomycin and teicoplanin, as well as ciprofloxacin, imipenem and cephalosporins. A special susceptibility to vancomycin is of great importance when choosing the antibiotic therapy. Vancomycin is the drug of choice for invasive infections caused by opportunistic Corynebacterium. Susceptibility to this antibiotic results in its high efficiency in the treatment of bacteremia $[41,42]$.

Ghide et al. [41], analyzing 98 patients who experienced Corynebacterium spp. infection, found that $94 \%$ of them were associated with the presence of vascular catheters, and the vancomycin therapy adopted in $64 \%$ of patients showed a positive effect on recovery without recurrence of fever. A major problem in the treatment of infections caused by opportunistic Corynebacterium spp. is the occurrence of multidrug resistance. It is also of importance for the antibiotic treatment of $S$. aureus infections [43].

The analysis of two groups of Corynebacterium showed significant differences in multiresistance to antibiotics. Among the isolates from the nose, none of the strains was simultaneously resistant to more than 6 classes of antibiotics, including erythromycin, clindamycin, chloramphenicol and trimethoprim/sulfamethoxazole. The results indicate that, although these bacteria are components of the physiological flora, they are not as commonly susceptible to antibiotics as one would expect. The use of antibiotics in patients with different types of infections may also affect saprophytic bacteria. This phenomenon is well known and may lead to the selection of resistant strains. Therefore, analysis of these processes, and the level at which they occur in the different groups of microorganisms, e.g. opportunistic Corynebacterium, is an important element in monitoring highly resistant strains derived from the saprophytic flora, particularly those which are simultaneously resistant to several antibiotics.

In the group of strains causing infections, the occurrence of multidrug resistance was observed in almost $20 \%$ of the isolates. Very important information is that the multidrug-resistant Corynebacterium strains still remained susceptible to vancomycin and teicoplanin, as described by other authors [13].

In the present study, the following species showed resistance to several groups of antibiotics: C. striatum, $C$. amycolatum, C. jeikeium and, which is particularly noteworthy, a rarely isolated species of C. glucuronolyticum in cases of bacteremia and secretions from the tracheostomy

Antibiotic Resistance and MLSB

Detection in Corynebacterium tube, i.e. probably derived from the hospital environment.

The results of this study confirm previous studies by other authors on the occurrence of multidrug-resistant strains among C. striatum [6], C. amycolatum [17, 44] and C. jeikeium [45].

This work and analyses stress that simultaneous resistance to macrolides (erythromycin) and lincosamides (clindamycin) occurred at a very high and equal level in both test groups, which indicates the presence of the cross-resistance mechanism MLSB. In addition, there was no significant difference between both groups, i.e. isolates from the nose and infections, in the number of strains with this mechanism of resistance.

A high level of resistance to macrolides and lincosamides in Corynebacterium is also reported by GómezGarcés et al. [13] and Fernandez-Roblas et al. [39].

Resistance within the MLSB mechanism is based on the production of rRNA methylase, which causes double methylation of adenine in 23S rRNA and results in a change in the structure of the antibiotic binding site. The gene erm encodes this enzyme [46], which belongs to class X for Corynebacterium [18]. Moreover, a case of isolation of Corynebacterium group A with the gene erm class B has been described [47].

The gene erm X was detected in different species of the genus Corynebacterium: C. diphtheriae [48], C. jeikeium [19], C. xerosis [19], C. striatum [5] and C. pseudodiphtheriticum.

The gene erm X may be located on plasmid pNG2 [49] within the transposon Tn5432 on R plasmid pTP10 [50] and on the chromosome [14].

It has been reported that multidrug resistance found in Corynebacterium spp. may be associated with the horizontal transfer of resistance genes with participation of strains of bacteria unrelated in terms of species and with displacement of the insertion sequence IS1249 and insertion and removal of Tn5432 [18]. It may be confirmed by the presence of Tn5432, for example, in Propionibacterium acnes, $P$. avidum and $P$. granulosum inhabiting the skin $[50,51]$. Own research related to opportunistic species of Corynebacterium showed that antibiotic resistance was significantly higher than that described for the potentially pathogenic, toxigenic and nontoxigenic $C$. diphtheriae. Zasada et al. [52], analyzing a clone of nontoxigenic C. diphtheriae occurring in Poland, pointed out that all of the test strains were susceptible to antibiotics. The MLSB mechanism, which is so popular among the opportunistic strains, was absent in all of the 19 strains studied. Gladin et al. [53] provided information about $11.5 \%$ of the $C$. 
diphtheriae resistant to erythromycin and lincomycin, which indicates that this mechanism is possibly also present in typically pathogenic species of Corynebacterium.

The phenotypic studies are the method of choice in routine detection of resistance mechanisms. If cross-resistant MLSB is found, which also occurs in staphylococci and streptococci, the so-called 'double-disk test' with erythromycin and clindamycin is used; it detects the presence of this mechanism in a simple and reliable way in routinely performed antibiograms.

The high percentage of strains with phenotypically detected constitutive-type resistance MLSB (high MICs) in this study indicates that the detection of the MLSB mechanism with the disk diffusion method with erythromycin and clindamycin could be helpful in routine diagnostics of infections caused by Corynebacterium spp., similar to its use in staphylococci and streptococci. Due to the lack of standardization of this method for the detection of the MLSB mechanism in species of the genus Corynebacterium, an attempt was made regarding its application. The aim of conducting research in this direction was to determine whether there is a correlation between the detection of the MLSB mechanism using the phenotypic method of the double-disk test and the presence of the gene erm X, which is responsible for this resistance mechanism. The occurrence of correlation would allow for the use of this method in routine microbiological diagnostics.

The MLSB mechanism was assessed in all strains of Corynebacterium spp. in both test groups, and determinations were made in accordance with hitherto existing recommendations [25].

If the use of the 'screening' method is intended for the detection of this resistance mechanism, the phenotypic studies cannot form the sole basis to determine its credibility. In such cases, the validity of the proceedings has to be confirmed by phenotypic and genetic tests in the same strains, which are performed in parallel, based on the detection of the presence of the gene responsible driving the mechanism of resistance.

A further step in research, the PCR method, was used to detect the presence of the gene erm $\mathrm{X}$ responsible for the cross-resistant MLSB in Corynebacterium spp. In strains of Corynebacterium randomly selected from the two study groups, i.e. from the nose and clinical material, three methods were combined to determine the presence of MLSB: the presence of the gene erm X was detected by PCR, MIC values for erythromycin and clindamycin were determined, and the test used for staphylococci and streptococci was performed using the disk diffusion method. A very high concordance between the phenotypic meth- od (two disks and MIC determination) and the detection of the presence of the gene erm X was noted. The results obtained indicate the possibility of application of the double-disk method for routine tests for resistant Corynebacterium, which will greatly facilitate the practical implementation of antibiograms for this group of bacteria.

In this study, the gene erm $\mathrm{X}$ was detected for example in C. accolens, C. tuberculostearicum, C. aurimucosum, C. pseudogenitalium and C. propinquum.

In the analysis of determinations of resistance of both groups of strains tested, attention was also paid to the high percentage of strains resistant to trimethoprim/sulfamethoxazole and chloramphenicol, which were derived from the mucous membranes of the nose and isolates from patients with various infections. The high percentage of Corynebacterium strains resistant to trimethoprim/ sulfamethoxazole in this study is certainly a phenomenon associated with the improper use of this sulfonamide in the treatment of various types of infections, which do not always require antibacterial treatment.

Resistance to $\beta$-lactam antibiotics in C. jeikeium, which poses a serious problem due to multidrug resistance, was analyzed by Lavollay et al. [54]. In the present study, a high sensitivity to $\beta$-lactam antibiotics was also found in Corynebacterium spp. from the nasal mucous membranes, whereas in strains obtained from various infections resistance ranged from 20 to $30 \%$.

Based on the conducted research and the present results on resistance to antibiotics in the Corynebacterium spp. tested, in addition to the common susceptibility to vancomycin and teicoplanin, it is worth noting that all strains from the mucous membranes of the nose and up to $90 \%$ of isolates from infections demonstrated a very high susceptibility to imipenem. Resistance to tetracycline and ciprofloxacin was practically restricted to strains isolated from infections.

\section{Conclusion}

The most common mechanism of resistance in strains of Corynebacterium isolated from the mucous membranes of the nose and various infections is the constitutive-type MLSB. In the antibiotic treatment of infections caused by opportunistic species of the genus Corynebacterium, a low therapeutic efficiency of macrolides, lincosamides and streptogramin B should be taken into account due to the high percentage of the constitutive-type resistance mechanism MLSB. 
The concordance of the phenotypic identification with genotypic studies (presence of the gene erm X) confirms the applicability of a simple phenotypic method of disk diffusion (erythromycin $15 \mu \mathrm{g}$ and clindamycin $2 \mu \mathrm{g}$ ) to detect the constitutive-type MLSB in Corynebacterium, the method used for staphylococci and streptococci, which may be applicable for the determination of drug resistance in routine microbiological diagnostics of infections caused by opportunistic Corynebacterium (coryneform).

\section{Acknowledgments}

I would like to express my gratitude to Dr. Marcin Niemcewicz of the Military Institute of Hygiene and Epidemiology, Biological Threat Identification and Countermeasure Center, Puławy, Poland, for his help in conducting the genetic research.

\section{Disclosure Statement}

The author has nothing to disclose.

\section{References}

1 Mookadam F, Cikes M, Baddour LM, Tleyjeh IM, Mookadam M: Corynebacterium jeikeium endocarditis: a systematic overview spanning four decades. Eur J Clin Microbiol Infect Dis 2006;25:349-353.

-2 Schoen C, Unzicker C, Stuhler G, Elias J, Einsele H, Grigoleil GU, Abele-Horn M, Mielke S: Life-threatening infection caused by daptomycin-resistant Corynebacterium jeikeium in a neutropenic patient. J Clin Microbiol 2009; 47:2328-2331.

- 3 Garcia-Bravo M, Aguado JM, Morale JM, Norwega AR: Influence of external factors in resistance of Corynebacterium urealyticum to antimicrobial agents. Antimicrob Agents Chemother 1996;40:497-499.

4 Dalal A, Urban C, Segal-Maurer S: Endocarditis due to Corynebacterium amycolatum. J Med Microbiol 2008;10:1299-1302.

$\checkmark 5$ Campanile F, Carretto E, Barbarini D, Grigis A, Falcone M, Goglio A, Venditti M, Stefani S: Clonal multidrug-resistant Corynebacterium striatum strains, Italy. Emerg Infect Dis 2009; 15:75-78.

-6 Otsuka Y, Ohkusu K, Kawamura Y, Baba S, Azeki T, Kimura S: Emergence of multidrugresistant Corynebacterium striatum as a nosocomial pathogen in long-term hospitalized patients with underlying diseases. Diagn Microbiol Infect Dis 2006;54:109-114.

7 Boltin D, Katzir MM, Bugoslavsky V, Yalashvili I, Brosh-Nissimov T, Fried, Elkayam O: Corynebacterium striatum - a classic pathogen eluding diagnosis. Eur J Inter Med 2009; 20:e49-e52.

$\checkmark$ Camello TC, Souza MC, Martins CA, Damasco PV, Marques EA, Pimenta FP, Pereira GA, Hirata R Jr, Mattos-Guarldi AL: Corynebacterium pseudodiphtheriticum isolated from relevant clinical sites of infection: a human pathogen overlooked in emerging countries. Lett Appl Microbiol 2009;48:458-464.

9 Manzella JP, Kellogg JA, Parsey KS: Corynebacterium pseudodiphtheriticum: a respiratory tract pathogen in adults. Clin Infect Dis 1995;20:37-40.

Antibiotic Resistance and MLSB

Detection in Corynebacterium
10 Joussen AM, Funke G, Joussen F, Herbertz G: Corynebacterium macginleyi: a conjunctiva specific pathogen. Br J Ophthalmol 2000;84: 1420-1422.

11 Funke G, Punter V, von Graevenitz A: Antimicrobial susceptibility patterns of some recently established coryneform bacteria. Antimicrob Agents Chemother 1996;40:28742878.

12 Funke G, von Graevenitz A, Clarridge JE 3rd, Bernard KA: Clinical microbiology of coryneform bacteria. Clin Micrbiol Rev 1997;1:125159 .

13 Gómez-Garcés JL, Alos JI, Tamayo J: In vitro activity of linezolid and 12 other antimicrobials against coryneform bacteria. Int J Antimicrob Agents 2007;29:688-692.

14 Roberts MC, Leonard RB, Briselden A, Schoenknecht FD, Coyle MB: Characterization of antibiotic-resistant Corynebacterium striatum strains. J Antimicrob Chemother 1992;30:463-474.

15 Tauch A, Krieft S, Pühler A, Kalinowski J: The tet $A B$ of the Corynebacterium striatum Rplasmid pTP10 encode an ABC transporter and confer tetracycline, oxytetracycline and oxacillin resistance in Corynebacterium glutamicum. FEMS Microbiol Lett 1999;173: 203-209.

16 Eguchi H, Kuwahara T, Miyamoto T, Nakayama-Imaohji H, Ichimura M, Hayashi T, Shiota H: High-level fluoroquinolone resistance in ophthalmic clinical isolates belonging to the species Corynebacterium macginleyi. J Clin Microbiol 2008;46:527-532.

17 Sierra JM, Martinez-Martinez L, Vazquez F, Giralt E, Vila J: Relationship between mutations in the gyrA gene and quinolone resistance in clinical isolates of Corynebacterium striatum and Corynebacterium amycolatum. Antimicrob Agents Chemother 2005;5:17141719.

18 Roberts MC, Sutcliffe J, Courvalin P, Jensen LB, Rood J, Seppala H: Nomenclature for macrolide and macrolide-lincosamidestreptogramin B resistance determinants. Antimicrob Agents Chemother 1999;43: 2823-2830.
19 Rosato AE, Lee BS, Nash KA: Inducible macrolide resistance in Corynebacterium jeikeium. Antimicrob Agents Chemother 2001; 7: 1982-1989.

20 Bernard KA, Munro C, Wiebe D, Ongsansoy E: Characteristics of rare or recently described corynebacterium species recovered from human clinical material in Canada. J Clin Microbiol 2002;40:4375-4381.

21 Drancourt M, Bollet C, Carlioz A, Martelin R, Gayral JP, Raoult D: 16S ribosomal DNA sequence analysis of a large collection of environmental and clinical unidentifiable bacterial isolates. J Clin Microbiol 2000;38:36233630.

-22 Fernández-Natal MI, Sáez-Nieto JA, Fernández-Roblas R, Asencio M, Valdezate S, Lapeña S, Rodríquez-Pollán RH, Guerra JM, Blanco J, Cachón F, Soriano F: The isolation of Corynebacterium coyleae from clinical samples: clinical and microbiological data. Eur J Clin Microbiol Infect Dis 2008;27:177-184.

23 CLSI: Method for Antimicrobial Dilution and Disk Susceptibility Testing of Infrequently Isolated or Fastidious Bacteria. Approved Standard M45-A, vol 26, No 19. Wayne, Clinical and Laboratory Standards Institute, 2009.

24 Etest Application Sheet EAS021: Fastidious Gram Positive Bacilli http://www.ilexmedical.com/files/Etest-ApplicationSheets/fastidiousgrampositivebacilli.pdf (accessed June 2, 2013).

25 CLSI: Performance Standards for Antimicrobial Susceptibility Testing; Twenty-First Informational Supplement. M100-S21, vol 31, No 1. Wayne, Clinical and Laboratory Standards Institute, 2011.

26 Fiebelkorn KR, Crawford SA, McElmeed ML, Jorgensen JH: Practical disk diffusion method for detection of inducible clindamycin resistance in Staphylococcus aureus and coagulasenegative staphylococci. J Clin Microbiol 2003; 41:4740-4744.

27 Otsuka Y, Kawamura Y, Koyama T, Iihara H, Ohkusu K, Azeki T: Corynebacterium resistens sp.nov, a new multi-resistant coryneform bacterium isolated from human infection. J Clin Microbiol 2005;8:3713-3717. 
28 Ahmed K, Kawakami K, Watanabe K, Mitsushima H, Nagatake T, Matsumoto K: Corynebacterium pseudodiphtheriticum: a respiratory tract pathogen. Clin Infect Dis 1995;20: 41-46.

29 Colt HG, Morris JF, Marston BJ, Sewell DL: Necrotizing tracheitis caused by Corynebacterium pseudodiphtheriticum: unique case and review. Rev Infect Dis 1991;13:73-76.

30 Bittar F, Cassagne C, Bosdure E, Stremler N, Dubus JC, Sarles J, Reynaud-Gaubert M, Raoult D, Rolain JM: Outbreak of Corynebacterium pseudodiphtheriticum infection in cystic fibrosis patients, France. Emerg Infect Dis 2010;16:1231-1236.

-31 Ang LM, Brown H: Corynebacterium accolens isolated from breast abscess: possible association with granulomatous mastitis. J Clin Microbiol 2007;45:1666-1668.

- 32 Claeys G, Vanhouteghem H, Riegel P, Wauters G, Hamerlynck R, Dierick J, de Witte J, Verschraegen G, Vaneechoutte M: Endocarditis of native aortic and mitral valves due to Corynebacterium accolens: report of a case and application of phenotypic and genotypic techniques for identification. J Clin Microbiol 1996;34:1290-1292.

-33 Wong JS, Seaward LM, Ho CP, Anderson TP, Lau EO, Amodeo MR, Metcalf SC, Pithie AD, Murdoch DR: Corynebacterium accolens-associated pelvic osteomyelitis. J Clin Microbiol 2010;48:654-655.

-34 Motomura K, Masaki H, Terada M, Onizuka T, Shimogama S, Furumoto A, Asoh N, Watanabe K, Oishi K, Nagatake T: Three adult cases with Corynebacterium propinquum respiratory infections in a community hospital (in Japanese). Kansenshogaku Zasshi 2004;78: 277-282.

35 Superti SV, Martins Dde S, Caierão J, Soares F, Prochnow T, Cantarelli VV, Zavascki AP: Corynebacterium striatum infecting a malignant cutaneous lesion: the emergence of an opportunistic pathogen. Rev Inst Med Trop São Paulo 2009;51:115-116.

- 36 Tibrewala AV, Woods CJ, Pyrgos VJ, Ruiz ME: Native valve endocarditis caused by $C$. striatum. Scand J Infect Dis 2006;38:805-807.

37 Martins C, Faria L, Souza M, Camello T, Velasco E, Hirata R Jr, Thuler L, MattosGuaraldi A: Microbiological and host features associated with corynebacteriosis in cancer patients: a five-year study. Mem Inst Oswaldo Cruz 2009;104:905-913.
38 Martínez-Martínez L, Suárez AI, Winstanley J, Ortega MC, Bernard K: Phenotypic characteristics of 31 strains of Corynebacterium striatum isolated from clinical samples. J Clin Microbiol 1995;9:2458-2461.

39 Fernandez-Roblas R, Adames H, Martín-deHijas NZ, Almeida DG, Gadea I, Esteban J: In vitro activity of tigecycline and 10 other antimicrobials against clinical isolatesof the genus Corynebacterium. Int J Antimicrob Agents 2009;33:453-455.

40 Espínola M, Somodevilla A, Domingo D, Alarcón T, López-Brea M: Antibiotic susceptibility of Corynebacterium macginleyi strains causing conjunctivitis (in Spanish). Rev Esp Quimioter 2010;23:196-200.

41 Ghide S, Jiang Y, Hachem R, Chaftari AM, Raad I: Catheter-related Corynebacterium bacteremia: should the catheter be removed and vancomycin administered? Eur J Clin Microbiol Infect Dis 2010;29:153-156.

42 Iroh Tam PY, Fisher MA, Miller NS: Corynebacterium falsenii bacteremia occurring in an infant on vancomycin therapy. J Clin Microbiol 2010;48:3440-3442.

43 Suzuki Y, Kawasaki K, Sato Y, Tokimatsu I, Itoh $\mathrm{H}$, Hiramatsu K, Takeyama M, Kadota J: Is peak concentration needed in therapeutic drug monitoring of vancomycin? A pharmacokinetic-pharmacodynamic analysis in patients with methicillin-resistant Staphylococcus aureus pneumonia. Chemotherapy 2012; 58:308-312.

44 Sánchez Hernández J, Mora Peris B, Yagüe Guirao G, Gutiérrez Zufiaurre N, Muñoz Bellido JL, Segovia Hernández M, García Rodríguez JA: In vitro activity of newer antibiotics against Corynebacterium jeikeium, Corynebacterium amycolatum and Corynebacterium urealyticum. Int J Antimicrob Agents 2003; 22:492-496.

45 Dinleyici EC, Yargic ZA, Bor O, Kiremitci A, Durmaz G: Tigecycline treatment of multidrug-resistant Corynebacterium jeikeium infection in a child with relapsing and refractory acute lymphoblastic leukemia. Pediatr Blood Cancer 2010;55:349-351.
46 Arthur M, Nolinas C, Mabilat C, Courvalin P: Detection of erythromycin resistance by the polymerase chain reaction using primers in conserved regions of erm rRNA methylase genes. Antimicrob Agents Chemother 1990; 10:2024-2026.

47 Luna VA, Coates P, Eady A, Cove JH, Nguyen TTH, Roberts MC: A variety of Gram-positive bacteria carry mobile mefgenes. J Antimicrob Chemother 1999;44:19-25.

48 Tauch A, Bischoff N, Brune I, Kalinowski J: Insights into the genetic organization of the Corynebacterium diphtheriae erythromycin resistance plasmid pNG2 deduced from its complete nucleotide sequence. Plasmid 2003; 49:63-74.

49 Coyle MB, Minshew BH, Bland JA, Hsu PC: Erythromycin and clindamycin resistance in Corynebacterium diphtheriae from skin lesion. Antimicrob Agents Chemother 1979;16: 525-527.

50 Ross JI, Eady AA, Carnegle E, Cove JH: Detection of transposon Tn5432-mediated macrolide-lincosamide-streptogramin B (MLSB) resistance in cutaneus propionibacterie from six European cities. J Antimicrob Chemother 2002;49:165-168.

51 El-Mahdy TS, Abdalla S, El-Domany R, Mohamed MS, Ross JI, Snelling AM: Detection of a new erm(X)-mediated antibiotic resistance in Egyptian cutaneous propionibacteria. Anaerobe 2010;16:376-379.

52 Zasada AA, Baczewska-Rej M, Wardak S: An increase in non-toxigenic Corynebacterium diphtheriae infections in Poland - molecular epidemiology and antimicrobial susceptibility of strains isolated from past outbreaks and those currently circulating in Poland. Int J Infect Dis 2010;14:e907-e912.

53 Gladin DP, Kozlova NS, Zaŭtseva TK, Cherednichenko AS, Khval SA: Sensitivity of Corynebacterium diphtheriae isolated in Saint-Petersburg to antibacterial drugs (in Russian). Antibiot Khimioter 1999;44:17-21.

54 Lavollay M, Arthur M, Fourgeaud M, Dubost L, Marie A, Riegel P, Gutmann L, Mainardi JL: The beta-lactam-sensitive D,D-carboxypeptidase activity of $\mathrm{Pbp} 4$ controls the L,D and D,D transpeptidation pathways in Corynebacterium jeikeium. Mol Microbiol 2009;74:650661. 